\title{
Graphene and Graphene Oxide-Based Membranes for Gas Separation
}

\author{
Nagapradeep Nidamanuri ${ }^{1 *}$, Yaqi $\mathrm{Li}^{1 / *}$, Qiang $\mathrm{Li}^{1^{*}}$ and Mingdong Dong ${ }^{2^{*}}$
}

Graphene has been hailed as a revolutionary membrane material because of its many alluring features and the ease in their tunability. In specific to gas separation industry, the exceptional molecular transport, the possibility of fabricating membranes having thickness at a nanoscale range and the robust lattice structure that can withstand to the rigorous perforation methods render graphene to stand ahead of its contemporary materials. Moreover, its broad chemical tolerance and high mechanical strength facilitate the mass-production of membranes possessing macroscopic dimensions and their subsequent long-term operation under harsh environments. In this concise review, we complied and discussed the progress of gas-separation performance of graphene-based membranes with a prime focus on recent advancements in scalability, functionalization/modification along with the new manufacturing processes including the budding approaches through synthetic chemistry. The strategies implemented, the factors that influenced the membranes' performance and the corresponding transport mechanisms were highlighted in detail. In the end, we outlined the daunting challenges facing by these graphene-based membranes in realization of their prospects as well as the proposed measures for alleviating them.

Keywords: Graphene; Graphene oxide; Membranes; Gas separation

Received 20 January 2020, Accepted 14 February 2020

DOI: $10.30919 / \mathrm{es} 8 \mathrm{~d} 128906$

\section{Introduction}

Gas separations through membranes has seen an incessant growth in the recent past because of its high-efficacy, lowcarbon footprint and modest energy requirements. ${ }^{1-5}$ Membranes can selectively transport species depending on their permeability and they can be functioned in an uninterrupted way with minimal maintenance. In general, polymers are used for making membranes owing to their notable gas-separation performance. But, their integral compromise between the permeability and selectivity (Robeson performance limit), mitigation of fouling and sensitivity towards high temperatures, harsh chemical environments ${ }^{6-8}$ led to search for other readily-available alternate membrane materials.

In this scenario, since from the discovery in 2004 by Geim and Novoselov, ${ }^{9}$ graphene-based materials have become an implicit choice for making membranes owing to their significant permeability, selectivity and mechanical tolerance even under harsh conditions. ${ }^{10-15}$ The pristine graphene layer was proven to be impermeable to any liquids/gases due to the insufficient narrow gaps in its atomic lattice structure. Moreover, its electron-rich skeletal features cause an additional repulsion towards penetrants. However, the random stacking of various graphene layers could develop nanochannels in interlayer spacings, thereby, opening up the opportunities for molecular transport. In addition, the dimensions of these nanochannels could be further tuned through functionalization (covalent/non-covalent) which dictate the selectivity and permeation of gas molecules.

Theoretical models such as classical molecular dynamics

${ }^{1}$ Key Laboratory of Colloid and Interface Chemistry of the Ministry of Education, and School of Chemistry and Chemical Engineering, Shandong University, Jinan 250100, China

${ }^{2}$ Interdisciplinary Nanoscience Center (iNANO), Aarhus University, Aarhus C, DK-8000, Denmark

${ }^{\#}$ These authors contributed equally to this work.

*E-mail: qiang@sdu.edu.cn (Q. Li); dong@inano.au.dk (M.D.Dong) 


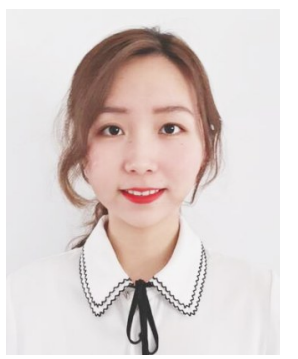

\section{Yaqi Li}

Yaqi Li is a master student since 2017 under the supervision of Prof. Qiang Li at School of Chemistry and Chemical Engineering, Shandong University, China. She received her BSc degree at College of Science, Northeastern University, China in 2017. Her current research focuses on synthesis of transition metal-based nanomaterials and their applications in energy conversion and storage.

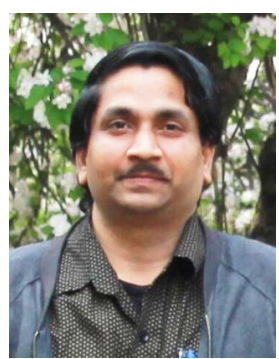

\section{Nagapradeep Nidamanuri}

Nagapradeep Nidamanuri acquired his PhD in Chemistry in 2015 from Indian Institute of Technology Kanpur (India). Later on, he did postdoctoral studies in USA for couple of years and then moved to China in 2017. At present, he is the recipient of Shandong University Foreign postdoctoral fellowship and his research is focused on fabricating novel nanostructured materials for energy and environmental applications.

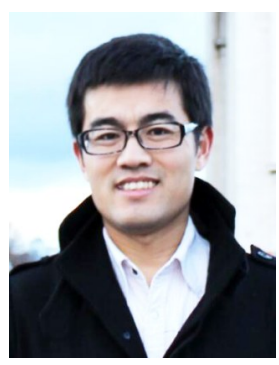

\section{Qiang Li}

Qiang Li received his PhD degree from Aarhus University, Denmark in 2014. After postdoctoral work at the Bio-SPM group, Aarhus University. he joined Shandong University as a professor in 2016. His current research focuses on the development of advanced atomic force microscopy for probing the physical and chemical properties of new functional materials at the nanoscale.

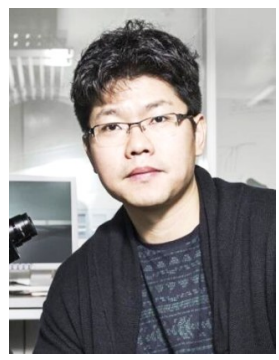

\section{Mingdong Dong}

Mingdong Dong obtained his PhD in Applied Physics from Aarhus University, Denmark in 2006. After postdoctoral research (Harvard University, USA), he started his independent academic career as Assistant Professor, and Associate Professor, Aarhus University. His research interests focus on both the implementation and further development of a novel scanning probe microscope technique to study molecular self-assembly for biological applications and new functional materials. 
and ab initio calculations forecasted that, when graphene is perforated systematically, it would become an ideal membrane material in terms of selectivity and permeability which can outperform the established polymer membranes. ${ }^{16}$ During the past few years, researches have revealed many encouraging facts and findings regarding the immense potential of graphenebased membranes for separating not only gases but also ions ${ }^{17-24}$ and liquids (aqueous/non-aqueous). ${ }^{25-28}$ In this concise review, we provide a brief synopsis of the recent advances in graphenebased gas-separable membranes and the challenges associated for their use as next-generation industrial membranes.

\section{Graphene}

Graphene (G), a two-dimensional $s p^{2}$-carbon sheet composed of a long-range conjugation across its honeycomb aromatic framework (Fig. 1a) ${ }^{29}$ Its high mechanical strength $\left(42 \mathrm{Nm}^{-1}\right)$, large Young's modulus ( $1.0 \mathrm{TPa})$, huge thermal conductivity $\left(4840-5300 \mathrm{~W} \mathrm{~m}^{-1} \mathrm{~K}^{-1}\right)$, and wide surface area $\left(2630 \mathrm{~m}^{2} \mathrm{~g}^{-1}\right)$ render graphene as a superior membrane material than other nanocarbon structures ${ }^{30,31}$ Moreover, its atomic thickness ( $0.34 \mathrm{~nm}$ ) will enable to make membranes having high permeate flux via lowering the transport resistance. Arcdischarge, carbon nanotubes (CNTs) unzipping, chemical vapor deposition (CVD) and epitaxial growth have been frequently utilized for its synthesis. ${ }^{32}$
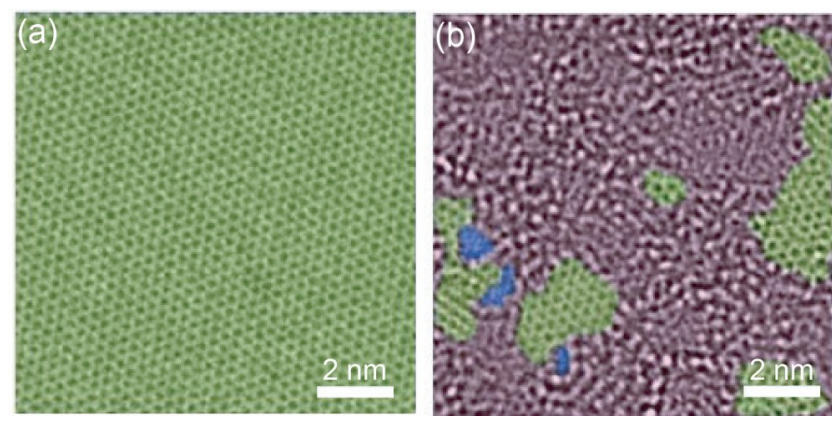

Fig. 1 TEM images of monolayered (a) graphene and (b) graphene oxide. (Both are adapted from Ref. [29], copyright 2010, with permission from WILEY-VCH Verlag GmbH \& Co. KGaA, Weinheim.)

The high-electron density of graphene will repel any atom/ molecule (except proton) trying to pass through its aromatic rings. ${ }^{33}$ Theoretical models suggested that the introduction of pores in graphene will induce superior permeation of different species selectively. The tuning of the geometry of the in-plane pores in single layer and the interlayer distances in multilayered graphene provide ancillary selective transport mechanisms. Both the top-down and bottom-up ways are developed to make nanopores in its sheet-like architecture. In top-down approach, techniques such as lithographic, hightemperature $\mathrm{O}_{2}$ exposure, UV-based oxidative etching are applied, while in bottom-up approach, chemical synthetic techniques are employed. ${ }^{34-39}$ Since the targeted pore sizes are $<$ $10 \mathrm{~nm}$, their systematic generation and distribution pose a major challenge to tackle with.

\section{Graphene Oxide}

Graphene oxide (GO), a layer-thin G derivative having many oxygen bearing moieties like carbonyl, carboxyl, hydroxyl and epoxy on its basal plane and edges (Fig. 2b). ${ }^{29} \mathrm{GO}$ is generally obtained from graphite crystals in two steps, in which, graphite is initially oxidized to graphitic oxide and then exfoliated to monolayered $\mathrm{GO}$ in alkaline conditions. For oxidation, strong oxidants such as $\mathrm{KMnO}_{4}$ in $\mathrm{HNO}_{3} / \mathrm{H}_{2} \mathrm{SO}_{4}, \mathrm{KClO}_{3}$ or $\mathrm{NaNO}_{2}$ are used, while for reduction, $\mathrm{NaBH}_{4}$ or $\mathrm{NH}_{2} \mathrm{NH}_{2}$ are preferred. ${ }^{40-42}$ If the reduction was carried out thermally in an inert atmosphere, reduced graphene oxide (rGO) will be obtained. ${ }^{43,44}$ In fact, $\mathrm{GO}$ can be chemically reduced to $\mathrm{G}$ but the high-cost limits this way of production. ${ }^{45}$

The distortions from the $s p^{3} \mathrm{C}-\mathrm{O}$ bonds cause nanoscale defects in the GO basal plane. These intrinsic faults behave as main pathways for gas molecules when membranes are fabricated ${ }^{46,47}$ Multiple functional groups' presence rendered GO to exhibit distinct properties than G, particularly, forming stable aqueous colloidal solutions without the aid of surfactants. This key feature was highly advantageous in membrane fabrication through simple solution based methods like spin/drop-casting. ${ }^{48,49}$ When dispersed in water, GO sheets are negatively charged due to the ionization of the carboxyl units on the edges, thereby opening up a new way of making composite membranes with disparate positively charged materials.

Moreover, the reactive functional groups of GO also furnish suitable sites for improving interactions with passing gases, thereby increasing the membrane performance significantly. Through surface-modification techniques, they further exploited for $\mathrm{GO}$ surface functionalization. In GO stacks, the degree of oxidation and the extent of solvent intercalation play a decisive role in creating large interlayer space $(0.7-1.2 \mathrm{~nm})$, through which the permeation of gas occurs unlike in monolayered $\mathrm{G}$ membranes, where the inplane pores provide transport channels. Intrinsic defects generated during the reduction of GO (i.e., rGO formation) can also act as nanopores. The dependence of such defect sizes on the synthetic parameters was computationally explored by Grossman's group recently. ${ }^{50}$ They demonstrated that the GO sheets having lower epoxy/hydroxyl ratio and O-concentrations need elevated reducing temperatures for generating $\mathrm{rGO}$ with suitable nanopores for gas separations.

\section{Monolayered Graphene Membranes}

Since pores are inevitable for gas transportation (Fig. 2a), a large number of theoretical studies explored the transport of different gases through single-layered graphene and its pore- 
functionalized derivatives. ${ }^{51}$ To compute transport properties, one of the two following approaches is often used-(i) Density functional (DFT) or other quantum mechanical techniques are employed for calculating the minimum energy required for a gas molecule for passing through a pore. Then, the permeance is approximated by implementing a transition state approach given the kinetic energy distribution of the gas molecules whereas the selectivity is determined as the ratio of Arrhenius factors. (ii) Classical molecular dynamics are applied for estimating the number of molecules tunneling through the pore which directly yields the permeance (Fig. 2b). ${ }^{52}$

For instance, Jiang's group ${ }^{53}$ computationally deposited a layer of ionic liquid- $(\mathrm{emim})\left(\mathrm{BF}_{4}\right)$ onto H-terminated porous graphene having $1 \mathrm{~nm}$ pores (Fig. 2c). This modification converted the nonselective large pores specific for gases having diameters of 3-4 $\AA$. Molecular dynamics simulations revealed that $\mathrm{CO}_{2}$ has much more permeance than $\mathrm{CH}_{4}, \mathrm{~N}_{2}$ because of pore-situated $\mathrm{BF}_{4}^{-}$, which offers additional affinity for $\mathrm{CO}_{2}$. Non-diffusible large [emim] $]^{+}$anchors this anion in its place through electrostatic attraction, thereby regulating the pore size. As a result, this composite membrane exhibited a permeance of $\sim 10^{5}$ GPU with a selectivity of 42 for $\mathrm{CO}_{2}$ over $\mathrm{CH}_{4}$. Further, they also demonstrated that the ionic liquid thickness and the sizes of anion or pores dictated the $\mathrm{CO}_{2}$ permeance and selectivity. Similar findings were also reported by Bai's team in their recent report,${ }^{54}$ in which the addition of partial negative charges on carbons enhanced $\mathrm{CO}_{2}$ affinity over $\mathrm{CH}_{4}$.

Despite of many theoretical calculations, the number of analytical evidences for gas transportation in graphene alone is still scarce in literature. Defect-free $G$ sheet was experimentally proven as impermeable to even He by Bunch et al. in 2008. ${ }^{55}$ Exfoliated nanoballoons of graphene were suspended over microcavities which remained gasimpermeable since the bare graphene was devoid of any defects and the carbon-carbon interspace was too short for a gas to permeate. Hence, piercing pores in graphene is mandatory for enabling their applicability in gas separations. But, the empirical growth of monolayered porous graphene membranes was very limited due to inadequate manufacturing processes and pore engineering techniques.

In general, large-scale $\mathrm{G}$ layers from nanometer size defects which hamper their efficiency through nonselective leakage of gas molecules. To circumvent this problem, Karnik's team implemented a porous anodic aluminum oxide support layer beneath the porous cm-long graphene (PG-AAO). ${ }^{56}$ Sequential ion bombardment and etching with $\mathrm{O}_{2}$ plasma created high density of sub-nanometer sized pores $\left(\sim 10^{11} \mathrm{~cm}^{-2}\right.$,

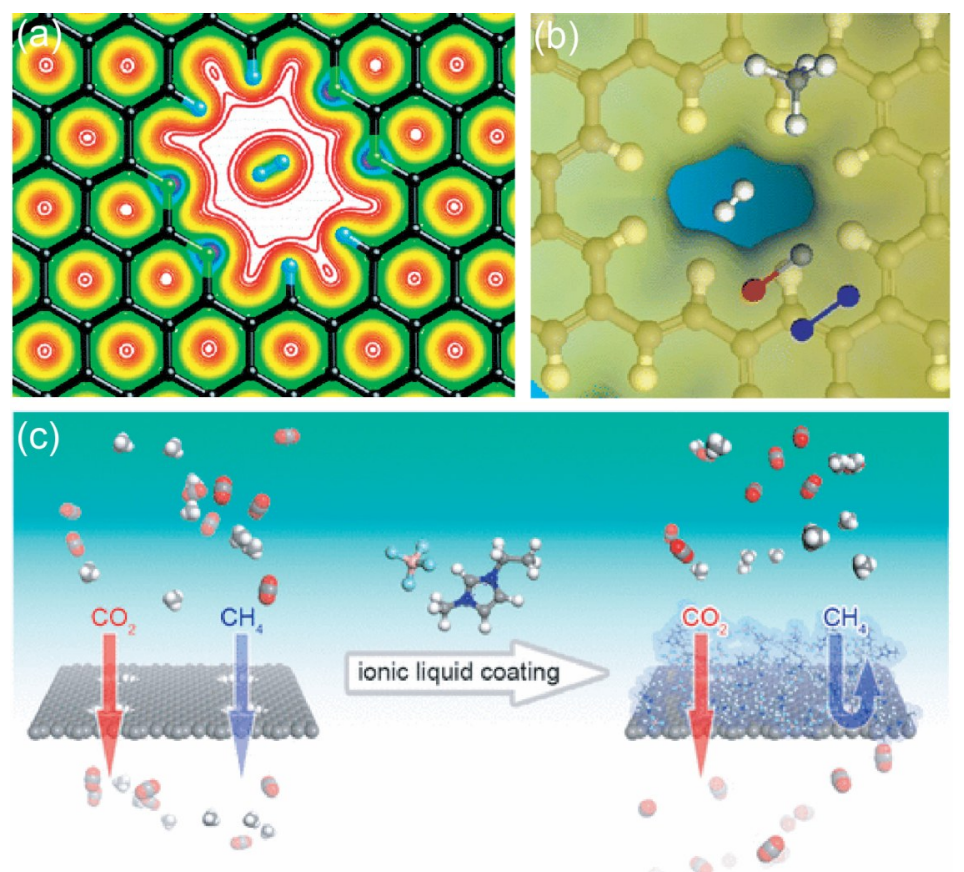

Fig. 2 (a) $\mathrm{H}_{2}$ separation through monolayer graphene having Nfunctionalized pores; (Adapted from Ref. [51], copyright 2009, with permission from American Chemical Society.) (b) Selective passage of $\mathrm{H}_{2}$ through single-layered porous graphene; (Adapted from Ref. [52], copyright 2014, with permission from American Chemical Society.) (c) Schematic illustration of selective $\mathrm{CO}_{2}$ separation by ionic-liquid coated porous graphene monolayer. (Adapted from Ref. [53], copyright 2017, with permission from American Chemical Society.) 
Fig. 3a). The selectivity was increased with increase in kinetic diameter of gas molecules and even exceeded the Knudsen effusion ratio. In case of $\mathrm{H}_{2} / \mathrm{CH}_{4}$ separation, the membrane performance was competitive, while in case of $\mathrm{H}_{2} / \mathrm{CO}_{2}$, it surpassed Robeson limit (Fig. 3b). However, the overall membrane has reduced permeance and selectivity because of AAO's limited porosity.

In a similar manner, Agarwal et al. ${ }^{57}$ fabricated four monolayered graphene membranes on W-support which perforated through $\mathrm{O}_{3}$ exposure. A tailor-made gas permeation module with mass spectrometer was built for assessing gas flux. These membranes had shown remarkable long-term stability even after harsh treatments like pressurizing $(>0.5$ bar) and heating (25 to $200{ }^{\circ} \mathrm{C}$ ) over weeks. However, the observed fluxes of all the gases $\left(\mathrm{CO}_{2}, \mathrm{CH}_{4}, \mathrm{He}, \mathrm{H}_{2}, \mathrm{SF}_{6}, \mathrm{Kr}\right)$ was far below than their technique's detection limit.

Experimental approaches for making quintessential quality of $\mathrm{G}$ sheets are still very limited, however, CVD process provides the best outcomes so far. ${ }^{58-60}$ In the recent past, the Samsung $^{61}$ and Sony ${ }^{62}$ electronics independently explored this technique for preparing 30-inch and $100 \mathrm{~m}$-long graphene on $\mathrm{Cu}$-substrates respectively. However, for membrane fabrication, the $\mathrm{G}$ layer needs to be transferred onto perforated supports like polymers. Such attempt was carried out by Paraense et $a l .{ }^{63}$ where they employed a wet-transfer technique. A cm-long mono/bi-G layer was successfully transferred onto polydimethylsiloxane (PDMS) in four steps by using poly (methyl methacrylate) (PMMA) as a sacrificial support. At first, PMMA was spin-coated onto the $\mathrm{Cu}$-supported $\mathrm{G}$, in the next step, the $\mathrm{Cu}$-support was removed with ammonium persulfate, and in the third step, the target PDMS support was introduced, while in the final step, PMMA was dissolved away with acetone. They found that the monolayer has modest increase in membrane barrier while in the bilayer, it increased by $30 \%$.

Extended tears and defects were commonly formed in $\mathrm{G}$ sheets while drying the solvents due to the presence of ample capillary force. This problem can be resolved via exposing the graphene surface directly without removing the mechanical supporting film. Such methodology was developed by
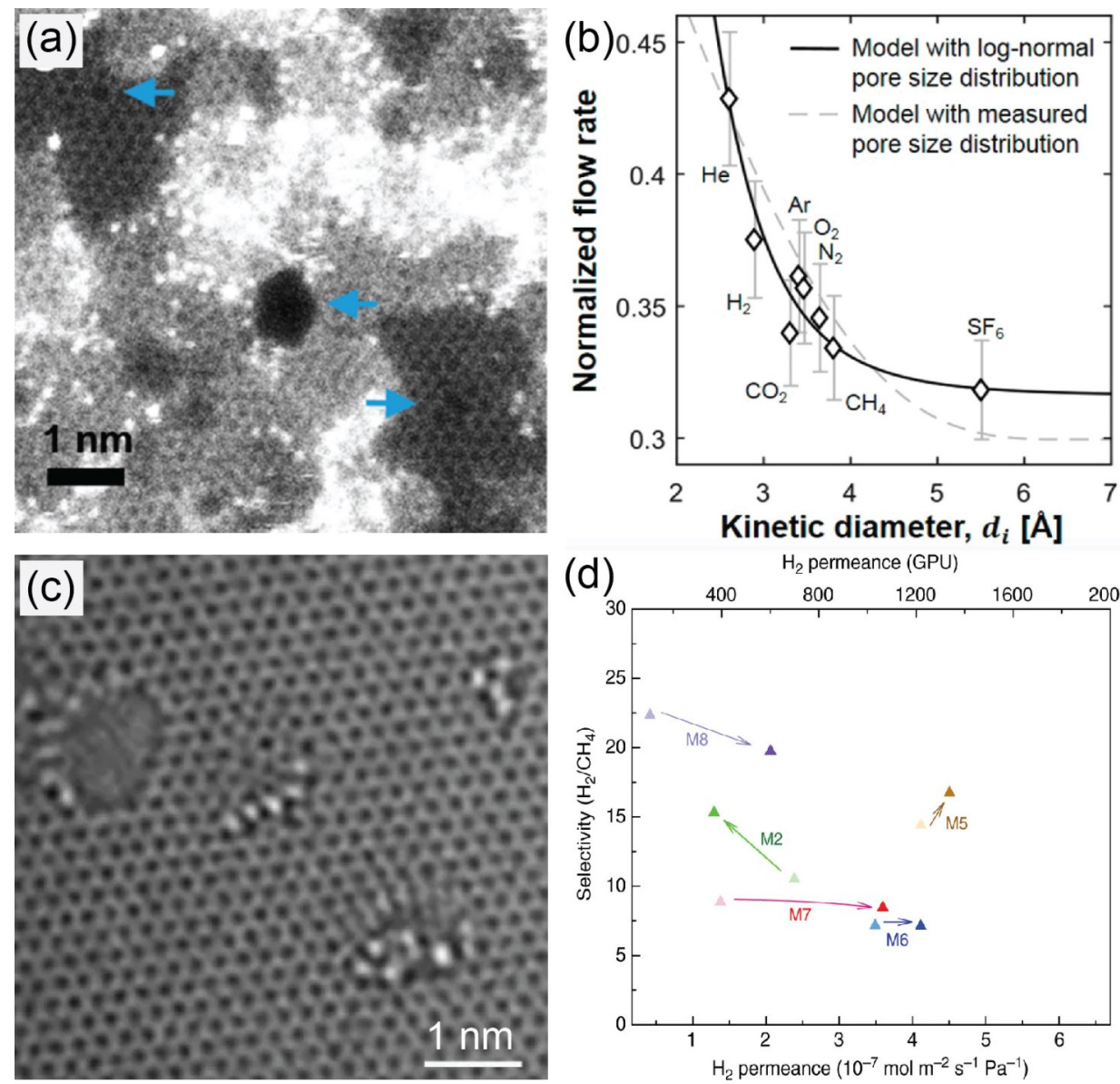

Fig. 3 (a) STEM image of perforated graphene layer; (b) Gas glow rates through PG-AAO membrane; (Both are adapted from Ref. [56], copyright 2017, with permission from American Chemical Society.) (c) HRTEM image of $\mathrm{O}_{3}$ functionalized graphene; (d) Gas separation performance various membranes after different $\mathrm{O}_{3}$ treatments. (Both are adapted from Ref. [64], copyright 2018, with permission from Macmillan Publishers Ltd.) 
Agarwal's team ${ }^{64}$ where they had grown a nanoporous carbon film (NPC) on top of graphene via coating a block copolymer followed by pyrolysis. Despite of its few intrinsic defects (5.4 $\times 10^{10} \mathrm{~cm}^{-2}$ ), the CVD-grown mm-long graphene monolayer displayed an attractive high permeance $\left(\sim 4.1 \times 10^{-7} \mathrm{~mol} \mathrm{~m}^{-2}\right.$ $\mathrm{s}^{-1} \mathrm{~Pa}^{-1}$ ) and selectivity (25) for $\mathrm{H}_{2}$ against $\mathrm{CH}_{4}$. Moreover, the etching of $\mathrm{H}_{2}$-selective pores with $\mathrm{O}_{3}$ raised its permeance by $\sim 300 \%$ and selectivity ( $\left(v \mathrm{CH}_{4}\right.$ ) by $\sim 150 \%$ as a result of porefunctionalization (Figs. 3c, d). In a recent report,$^{65}$ this team further increased the pore density to $2.1 \times 10^{12} \mathrm{~cm}^{-2}$ by consecutive $\mathrm{O}_{2}$ plasma and $\mathrm{O}_{3}$ exposures which resulted a record-high mixed-gas separation performance (Separation factor for $\mathrm{H}_{2} / \mathrm{CH}_{4}=15.6$ to 25.1 and for $\mathrm{H}_{2} / \mathrm{C}_{3} \mathrm{H}_{8}=38.0$ to 57.8).

In most of the literature reported findings, the permeance of single component gases was mostly investigated, but, it can't consider the competitive adsorption and diffusion arose in case of gas mixture separations. Strano's group ${ }^{66}$ made such an attempt in 2018, in which, equimolar gas mixtures of $\mathrm{CH}_{4}$, $\mathrm{CO}_{2}, \mathrm{H}_{2}, \mathrm{He}$ and $\mathrm{SF}_{6}$ were implemented. Five porous graphene membranes A, A', B, C and D were made through CVD and then transferred to Ni-supports (pore $\mathrm{D}=\sim 5 \mu \mathrm{m}$ ). By using mass spectrometer, the temperature-dependent permeance was measured from 22 to $208{ }^{\circ} \mathrm{C}$. It is found that gas-permeable nanopores of various diameters were formed spontaneously in all membranes except $\mathrm{D}$. Membranes A and $\mathrm{A}^{\prime}$ (pore $\mathrm{D}=\sim 2.5$ $\mathrm{nm}$ ) evinced $10^{-6}-10^{-5} \mathrm{~mol} \mathrm{~m}^{-2} \mathrm{~s}^{-1} \mathrm{~Pa}^{-1}$ gas permeance with selectivity beyond Knudsen limit because of steric selectivity mechanism. But, the membrane B (pore $\mathrm{D}=\sim 100 \mathrm{~nm}$ ) exhibited lower selectivity than Knudsen effusion limit due to consolidation of viscous flow and effusion. Temperaturedependent higher permeance rates were observed in case of membrane $\mathrm{C}$ as a consequence of activated translocation via nanopores. For instance, at $200{ }^{\circ} \mathrm{C}$, it shown a selectivity of $>$ 20 for $\mathrm{CO}_{2}$ over $\mathrm{SF}_{6}$

\section{Few-Layered Graphene/Graphene Oxide-Based Membranes}

The possible control over etching and enhanced pores' stability in bilayered graphene ${ }^{67}$ had drawn significant interest for making few-layered porous graphene membranes for gas separations. In 2012, Bunch's group ${ }^{68}$ drilled $\AA$-sized pores (3.4 and 4.9) in bilayer graphene by oxidative etching with UV light. A blister test and mechanical resonance were applied for deducing the transport properties of gas molecules. The obtained $\mathrm{H}_{2}(4.5(3.4 \AA), 75(4.9 \AA))$ and $\mathrm{CO}_{2}(2.7(3.4 \AA), 25$ $(4.9 \AA)$ ) permeances (in $10^{-23} \mathrm{~mol} \mathrm{~s}^{-1} \mathrm{~Pa}^{-1}$ ) were in well agreement with theoretical models in the literature (Fig. 4a). In the next year, Kim et al. ${ }^{69}$ deposited various $\mathrm{G}$ sheets onto a highly permeable glassy polymer support - poly(1trimethylsilyl-1-propyne) (PTMSP). The defects generated during fabrication process rendered significant gas permeability but it is decreased with increase in number of $\mathrm{G}$ layers deposited (Fig. 4b). Celebi et al. ${ }^{70}$ accounted much higher gas permeance where CVD-grown bilayer graphene was transferred onto $\mathrm{SiN}_{\mathrm{x}}$ and $7.6 \mathrm{~nm}-1 \mu \mathrm{m}$ diametered pores were created by exposure to He beam (Fig. 4c). This Knudsen effusion-based membrane exhibited higher permeance $\left(\sim 10^{-2}\right.$ mol m $\left.\mathrm{m}^{-2} \mathrm{~s}^{-1} \mathrm{~Pa}^{-1}\right)$ than traditional polymeric membranes with comparable $\mathrm{H}_{2} / \mathrm{CO}_{2}$ selectivity of $\sim 3.4$. Similarly, while in case of perforated PDMS-coated trilayered graphene membranes (cm-range) on polycarbonate supports developed by Karnik's team, ${ }^{71}$ the selectivity was close to Knudsen effusion limit and the gas separation was depended primarily on the mass of gas molecules rather than their kinetic diameters.

Few-layered graphene-derived membranes are more commonly built from GO because of its large-interlayered spacing lamellar structure $(0.6-1 \mathrm{~nm})$ which offers prolonged diffusional channels that can provide high energy barriers and pressure gradients for gas diffusion. The earlier report came from Park's team ${ }^{69}$ in 2013 where GO dispersion was spin-
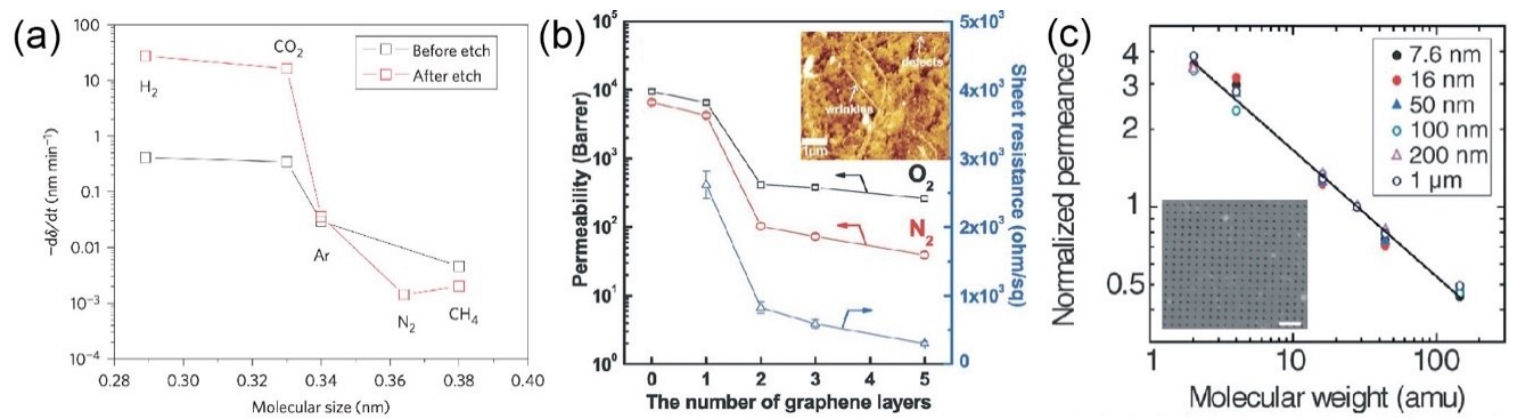

Fig. 4 (a) Comparison of gas separation performance of perforated bilayered graphene before and after etching; (Adapted from Ref. [68], copyright 2012, with permission from Macmillan Publishers Ltd.) (b) Change in gas flow with number of graphene layers deposited; (Adapted from Ref. [69], copyright 2013, with permission from American Association for the Advancement of Science.) (c) Gas permeances of graphene membranes with different pore diameters. (Adapted from Ref. [70], copyright 2014, with permission from American Association for the Advancement of Science.) 
casted onto a polyethersulfone (PES) support in two different ways. TEM imaging revealed 3-7 nm sized GO coating (Figs. $5 \mathrm{a}, \mathrm{b})$ and the gas permeances were determined under dry and humidified conditions. The membranes made from method-1 shown more gas permeability while the membranes from method-2 exhibited better gas selectivity because of their highly interlocked layered structures (Figs. 5c, d). Many factors such as the fabrication route, size and stacking manner of $\mathrm{GO}$, amount of intercalated water are known to be influential in determining the gas transportation properties. Further, in the same year, Li et al. ${ }^{72}$ also described that the GO membranes' gas permeance mainly dictated by their thickness with preferentiality towards ultrathin size $(1.8 \mathrm{~nm})$.

The hydrophilicity arisen from GO's oxygen-containing functional groups is known to aid the gas separations unlike conventional zeolitic, hydrophobic polymer membranes where
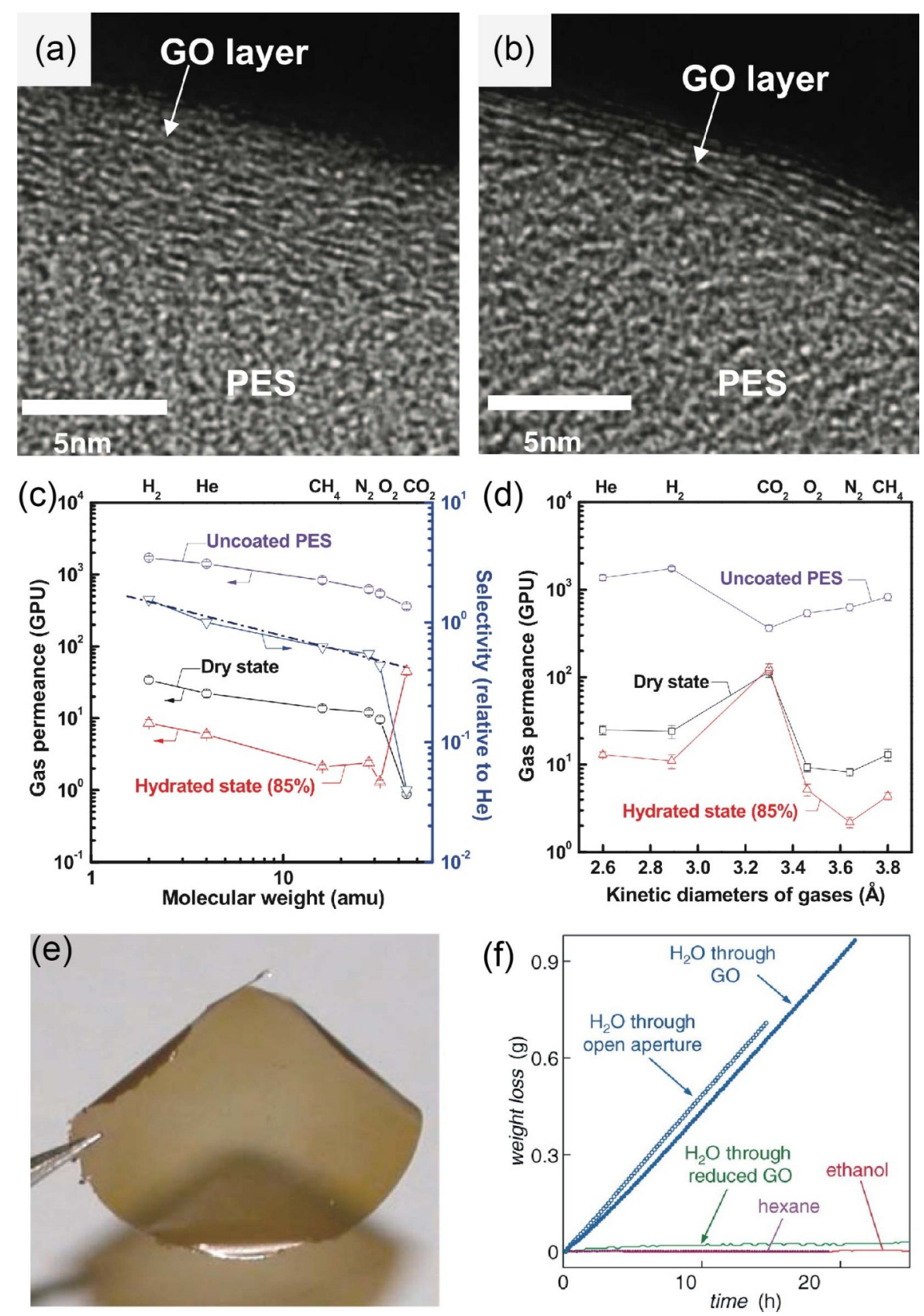

Fig. 5 (a, b) TEM images of GO membranes made from method-1 and 2 respectively; (c, d) Dependence of gas permeances on the molecular weight (method-1) and kinetic diameter of gases (method-2) respectively; (All are adapted from Ref. [69], copyright 2013, with permission from American Association for the Advancement of Science.) (e, f) Photo of a 1-mm-thick GO film and permeation through hydrated GO film. (Adapted from Ref. [73], copyright 2012, with permission from American Association for the Advancement of Science.) 
the condensation of water vapor reduces selectivity and permeability. Such water-enhanced separations were analytically proven initially by Nair et al. where the hydrated GO sheets are permeable to He but not the dried ones. This was mainly resulted from the enlarged interlayer spacing due to intercalation of water in GO stacks (Figs. $5 \mathrm{e}, \mathrm{f}$ ) ${ }^{73}$ Such waterintercalation in $\mathrm{GO}$ also raised the $\mathrm{CO}_{2}$ sorption as accounted by Ho Bum Park's group. ${ }^{74}$ These authors made ultrathin GO membranes of thickness $<5 \mathrm{~nm}$ on a microporous PES support which displayed higher selectivity for $\mathrm{CO}_{2}$ over gases like $\mathrm{H}_{2}$, $\mathrm{N}_{2}$ and $\mathrm{CH}_{4}$ under humidified feed streams. Such water-tolerant gas-separable GOs are of much demand in industriallyimportant water-sensitive separation processes such as natural gas refinement, post-combustion $\mathrm{CO}_{2}$ capture owing to the ease in applicability of dehydration at permeate end rather than highpressure feed end.

In 2016, Zhao's group ${ }^{75}$ utilized AAO substrates for assembling GO membranes through a three-step strategy where the mild freeze-thaw exfoliated pure GO sheets were spincasted. These membranes displayed superior performance $\left(\mathrm{H}_{2}\right.$ permeance $\left.=6.7 \times 10^{-7} \mathrm{~mol} /\left(\mathrm{m}^{2} \mathrm{~s} \mathrm{~Pa}\right) ; \mathrm{H}_{2} / \mathrm{CO}_{2}=240\right)$ than pervious findings, while at $120{ }^{\circ} \mathrm{C}$, the separation factor was reduced to 47 while the $\mathrm{H}_{2}$ permeance was raised to $6.7 \times 10^{-7}$ $\mathrm{mol} /\left(\mathrm{m}^{2} \mathrm{~s} \mathrm{~Pa}\right)$. In the next year, Qi et al. ${ }^{76}$ electrodeposited defect-free GO sheets onto porous stainless-steel hollow fiber (PSSHF) where the GO's oxygen-containing groups were exclusively reduced, thereby, yielded much narrow channels within the stacked layers. These 95-nm thickened composite membranes (GO@PSSHF) showed a selectivity of 551,319, 332 and 192 for $\mathrm{C}_{2} \mathrm{H}_{4} / \mathrm{C}_{3} \mathrm{H}_{8}, \mathrm{C}_{2} \mathrm{H}_{4} / \mathrm{C}_{3} \mathrm{H}_{6}, \mathrm{C}_{2} \mathrm{H}_{6} / \mathrm{C}_{3} \mathrm{H}_{8}$ and $\mathrm{C}_{2} \mathrm{H}_{6} /$ $\mathrm{C}_{3} \mathrm{H}_{6}$ mixtures respectively, which were higher than their
Knudsen selectivities $(\sim 1.2)$. While in case of binary gas mixtures that were comprising a $\mathrm{C} 3$ hydrocarbon and a small gas $\left(\mathrm{H}_{2}, \mathrm{CH}_{4}\right.$ or $\mathrm{C} 2$ hydrocarbon), the permeance of small gases remained same but for $\mathrm{C} 3$ hydrocarbons it is increased when compared to single-gas measurements.

In recent times, porous ceramic supports having much stability and robustness were preferentially explored. They offer low transport resistance and higher area/volume ratio which minimize the volume of membranes required for separations, thereby, reducing the operational cost and investment drastically. Zhu et al. ${ }^{77}$ applied such hollow fiber ceramic supports - yttrium-stabilized zirconia (YSZ) for developing highly-stable $\mathrm{GO}$ membranes permeable for $\mathrm{H}_{2}$ $\left(4.46 \times 10^{-8} \mathrm{~mol} \mathrm{~m}^{-2} \mathrm{~s}^{-1} \mathrm{~Pa}^{-1}\right)$. Vacuum-suction impregnation method was employed for engineering large area $\left(12 \mathrm{~cm}^{2}\right)$ membranes (GO/YSZ) having $\mathrm{H}_{2}$ selectivity of $76\left(\mathrm{vs} \mathrm{N}_{2}\right)$ with a separation factor of 68 at $20{ }^{\circ} \mathrm{C}$. Subsequent simulation studies revealed that the front part (near the inlet) of the YSZ contributed more towards the overall $\mathrm{H}_{2}$ permeance than the rear part.

\section{Graphene Oxide-Based Polymeric Composite Membranes}

Graphene layers are found to be less compatible with many polymers resulting gaps surrounding them. The gas molecules would flow through these gaps and exhibit a low gas barrier performance due to the decreased diffusion tracts. Moreover, because of the high aspect ratio, the graphene platelets behave like physical barriers for the polymer rearrangement and the diffusion of free volume domains, thereby, resulting the ageing. ${ }^{78}$ Graphite exfoliation in a microporous polymer ${ }^{79,80}$ is
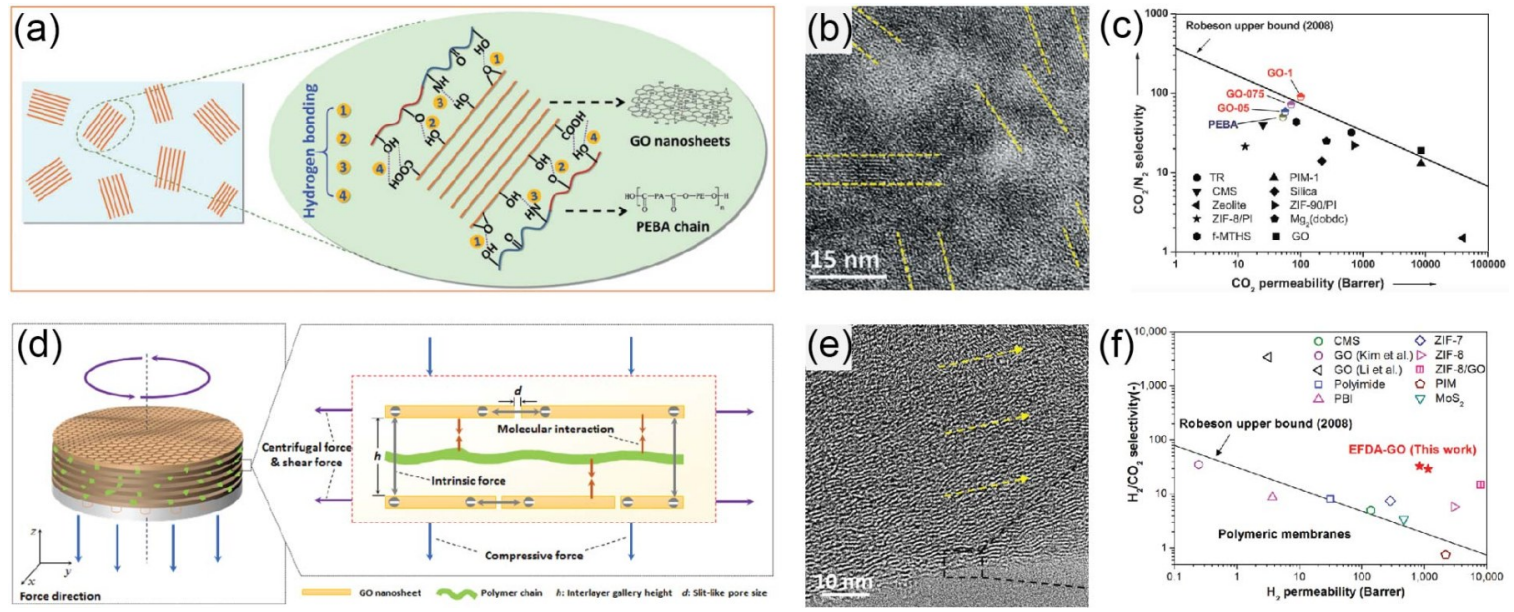

Fig. 6 (a) Schematic illustration of H-bonding between PEBA chain and GO nanosheets; (b) GO laminates in TEM image of GO-PEBA membranes; (c) $\mathrm{CO}_{2} / \mathrm{N}_{2}$ separation performance of membranes with different GO concentrations (All are adapted from Ref. [85], copyright 2015, with permission from WILEY-VCH Verlag GmbH \& Co. KGaA, Weinheim.) (d) External force driven assembly approach for fabricating EFDA-GO membranes; (e, f) TEM image and $\mathrm{H}_{2} / \mathrm{CO}_{2}$ separation of EFDAGO membranes respectively. (All are adapted from Ref. [86], copyright 2016, with permission from American Chemical Society.) 
normally carried out for making the respective composite membranes, however, the molecular simulations confirmed the alteration of polymer distribution even at very low loadings of graphene. ${ }^{81}$ Surface modification of graphene with suitable agents will resolve some of these issues to a greater extent and also offers an additional mechanical strength to membranes. It was found that the membrane design and performance mainly affected by the functionalization of $\mathrm{G}$, the interfacial interactions (e.g. H-bonding, electrostatic/hydrophilic, $\pi-\pi$ ) between polymer matrix and $\mathrm{G}$ layers, and the processing technique and parameters.

In case of GO, it is known that the electrostatic repulsion arising from the carboxyl groups in interlayers causes undesirable cracks that led to mechanical instability of the membranes. To reduce such unwanted interlamellar interactions, a variety of natural and synthetic polymers ${ }^{82-84}$ are often employed between the GO layers. Shen et al. ${ }^{85}$ utilized polyether block amide (PEBA) to create stable GO laminates (Figs. $6 \mathrm{a}, \mathrm{b} ; d$-spacing $=0.7 \mathrm{~nm}$ ) having straight diffusion pathways. The $-\mathrm{N}-\mathrm{H}-, \mathrm{H}-\mathrm{N}-\mathrm{C}=\mathrm{O}$, and $\mathrm{O}-\mathrm{C}=\mathrm{O}$ moieties of the polymer were involved in strong $\mathrm{H}$-bonding with the functional groups of GO. By varying GO concentration, these composite membranes showed excellent $\mathrm{CO}_{2} / \mathrm{N}_{2}$ permeance of 100 Barrer and selectivity of 91 with notable operational stability $(>6000$ min) (Fig. 6c). In another report, ${ }^{86}$ these authors used a positively charged polymer-poly(ethyleneimine) (PEI) for engineering GO membranes with much lower $d$-spacing $(\sim 0.4$ $\mathrm{nm})$. Through external force driven assembly (EFDA) approach, they controlled the external forces while coating GO and PEI solutions alternatively onto AAO substrates (Fig. 6d). The formed EFDA-GO membranes were highly-ordered with well aligned slit-like pores and interlayer-galleries (Fig. 6e). Their $\mathrm{H}_{2} / \mathrm{CO}_{2}$ permeability (840/1200 Barrer) and selectivity (29/33) is far ahead of many of commercial membranes (Fig. $6 f)$.

Recently, Pierleoni et al..$^{87}$ applied the same PEI polymer for creating stable multilayered GO composites having a constant spacing of $3.7 \mathrm{~nm}$. Through the dip casting process, a positively charged polymer covering is initially developed on polyethylene terephthalate (PET) and matrimid substrates which subsequently dipped in negatively charged GO to create bilayered composites. These steps are repeated number of times to get the thicker multilayered composite membranes where the polymeric chains behave like molecular spacers for GO sheets resulting high stability. These GO-PEI-BL membranes showed remarkable $\mathrm{He}$ gas selectivity of 500 (vs $\mathrm{CO}_{2}$ ), which is beyond the Robeson limit. In case of $\mathrm{He} / \mathrm{CO}_{2}$ and $\mathrm{H}_{2} / \mathrm{CO}_{2}$ mixtures, the permeability depended exponentially on the penetrant's kinetic diameter.

Polymeric matrices that selectively facilitate the gas transport are also exploited for boosting the membranes' gasseparation performance. Wang et al. ${ }^{88}$ embraced this idea by cross-linking GO sheets with poly(ethylene glycol) diamines (PEGDA), where PEG imparted additional affinity towards $\mathrm{CO}_{2}$. GO's epoxy groups reacted with the polymer and created both the $\mathrm{CO}_{2}$-philic (intercalated with polymer) and non- $\mathrm{CO}_{2}$ philic (unmodified graphene regions) nanodomains across GO (Fig. 7a). The GO-PEGDA500 membranes showed a significant permeance for $\mathrm{CO}_{2}(175.5 \mathrm{GPU})$ with a selectivity of $69.5\left(\mathrm{vs} \mathrm{CH}_{4}\right)$ as depicted in Fig. 7b. Hong's group ${ }^{89}$ described similar study where polyelectrolyte-supported wellordered GO membranes are developed. A spray-assisted layerby-layer method and $\mathrm{pH}$ adjustment is used for precisely controlling the thickness of GO sheets. The supporting matrix of the repeating poly(diallyldimethylammonium chloride)/ polystyrene sulfonate layers was first deposited onto the porous polysulfone (PSF) surface, and then GO sheets were introduced selectively. The high-density of polar groups on GO and the $\mathrm{NH}_{2}$ groups in the polyelectrolyte layers resulted a prominent $\mathrm{CO}_{2}$ permeance (1175.0 GPU) with a selectivity of 15.3 against $\mathrm{N}_{2}$.

In contrast, some research teams implemented $\mathrm{CO}_{2}$-philic $\mathrm{GO}$ instead of $\mathrm{CO}_{2}$-philic polymeric matrices. They functionalized $\mathrm{GO}$ via oxygen-containing groups $(-\mathrm{OH}$, $\mathrm{COOH}$ ) with $\mathrm{CO}_{2}$-philic groups which improved the interfacial interactions of polymeric matrix with GO. He's team ${ }^{90}$ impregnated imidazole functionalized GO (ImGO) into poly (ether-b-amide) (PEBAX) matrix. These ImGO@PEBAX membranes displayed $\mathrm{CO}_{2}$ permeability of 76.2 Barrer with selectivity of 105.5 ( $\mathrm{vs} \mathrm{N}_{2}$ ) at 0.8 wt.\% loading of ImGO. BaoSheng Ge et al. ${ }^{91}$ aminated GO with ethylene diamine (EA-GO) and incorporated it into the polyamide acid. The in-situ polymerization developed the composite membranes (EAGO@PI) with high $\mathrm{CO}_{2}$ affinity. The $\mathrm{CO}_{2} / \mathrm{N}_{2}$ separation performance increased with the increase of GO loading and reached a maximum at $3 \mathrm{wt} . \%\left(\mathrm{CO}_{2}\right.$ permeability $=12.34$ Barrer; $\mathrm{CO}_{2} / \mathrm{N}_{2}$ selectivity $=38.56$ ).

Wang et al..$^{92}$ prepared two isocyanated GOs in the similar manner with 2, 4-tolylene diisocyanate (TDI) and dicyclohexylmethylmethane-4, 4'-diisocyanate (HMDI). The respective membranes were made via in-situ polymerization with 4, 4'-diaminodiphenylether and 4, 4'-(hexafluoroisopropylidene)diphthalic anhydride. As TDI is less symmetrical than HMDI, the GO-TDI has plenty of isocyanate moieties and surface defects which resulted better dispersion than GOHMDI during membrane fabrication. At $30 \mathrm{wt} . \%$ loading of GO-TDI, the membranes evinced best $\mathrm{CO}_{2} / \mathrm{N}_{2}$ permeance and selectivity. Moreover, this team ${ }^{93}$ also grafted PEG with different molecular weights and created PEG-GO@PI membrane. The PEG modification not only altered the surface properties of GO but also caused plenty of defects which improved the separation ability markedly. PEG200-GO@PI, PEG600-GO@PI showed high $\mathrm{CO}_{2}$ and $\mathrm{N}_{2}$ diffusion whereas membranes with PEG1000-GO, PEG1500-GO and PEG2000- 
$\mathrm{GO}$ exhibited high $\mathrm{CO}_{2}$ permeance because of the raise in polar groups into the polymeric matrix.

Periodic crosslinking of GO with molecules that have multiple binding sites is proven as another efficient way to increase the mechanical strength of GO membranes. Recently, Sun's research team ${ }^{94}$ successfully fabricated thioureacrosslinked GO framework membranes (TU-GOF) onto porous alumina tubes via a simple hydrothermal layer-by-layer selfassembly process. The condensation reactions between $-\mathrm{NH}_{2} /-$
$\mathrm{SH}$ with $-\mathrm{COOH}$ and the nucleophilic addition of $-\mathrm{NH}_{2}$ to $\mathrm{C}-\mathrm{O}-$ $\mathrm{C}$ yielded thiourea-bridged periodic GO laminates (Fig. 7c). Structurally well-defined 2D narrow channels were developed between stacked GO layers due to the small interlamellar thiourea linker. These composite membranes exhibited an impressive $\mathrm{H}_{2}$ permeance against $\mathrm{CO}_{2}$ (Fig. 7d), which is far ahead of Robeson upper limit.

In addition, ionic liquids that show high $\mathrm{CO}_{2}$ solubilities are also applied. Their miscibility with aqueous solutions plays (a)

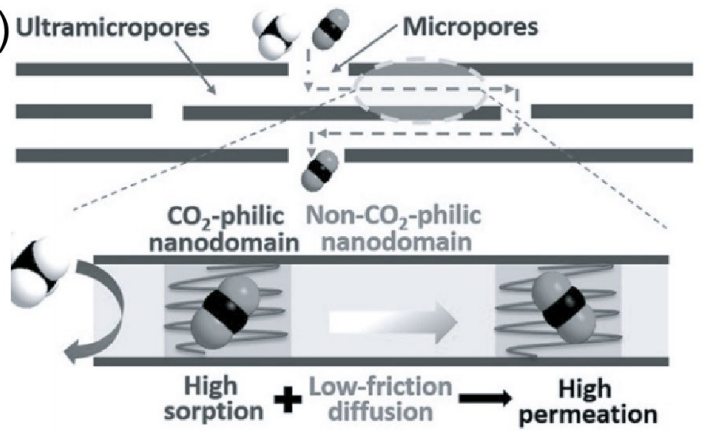

(c)

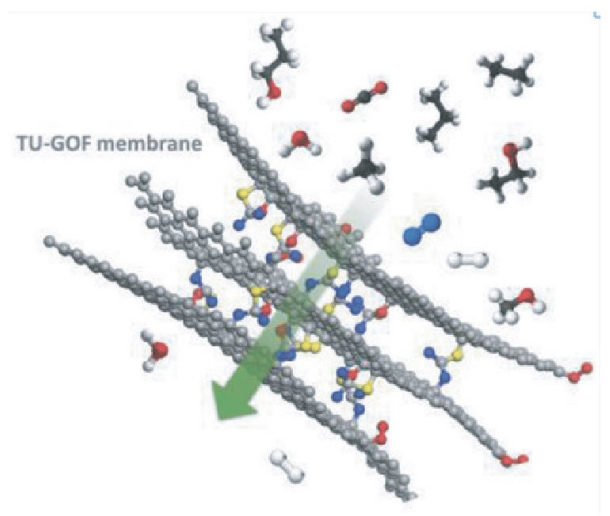

(e)

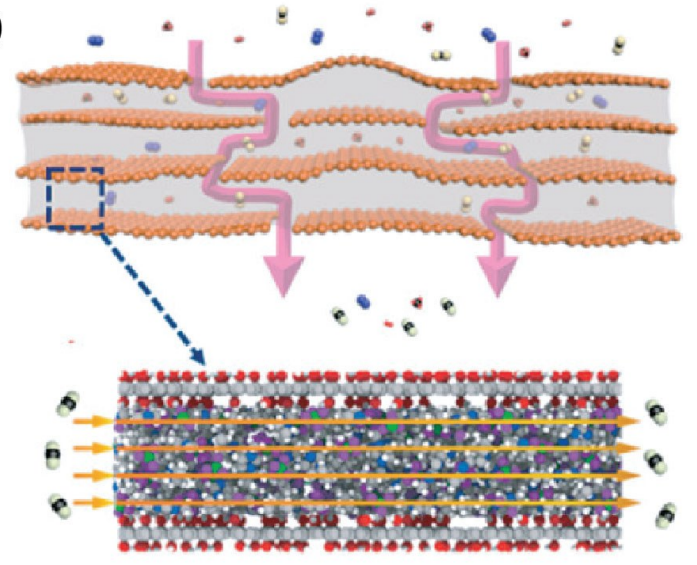

(b)

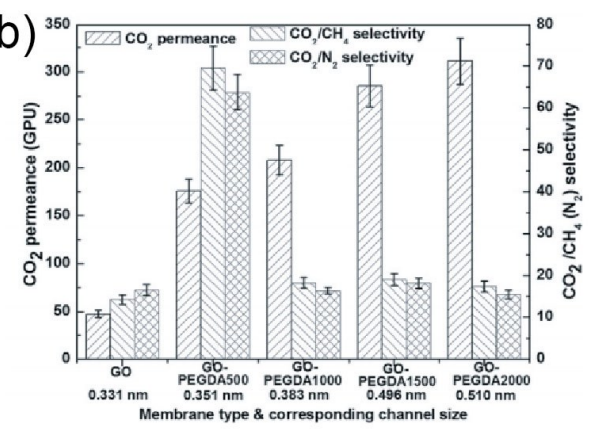

(d)

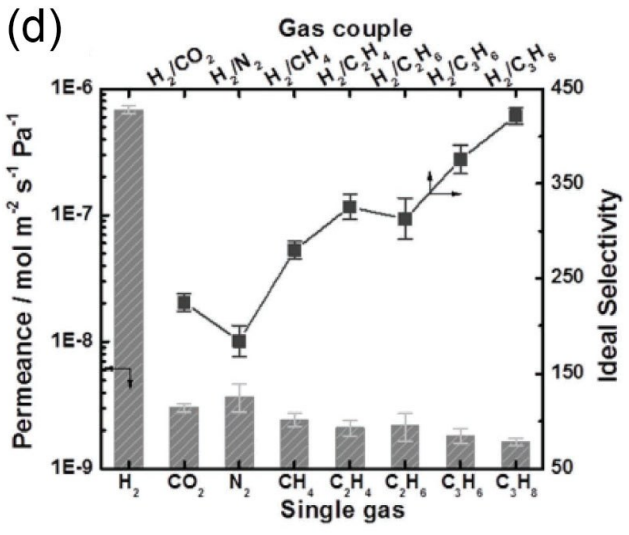

(f)

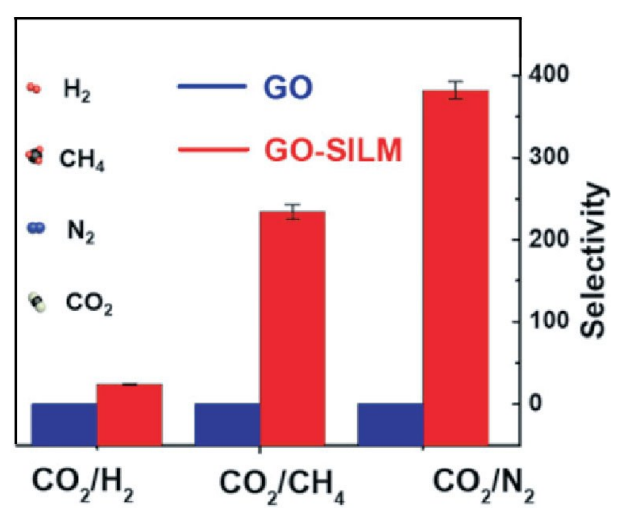

Fig. 7 (a) Representation of the both the $\mathrm{CO}_{2}$-philic and non- $\mathrm{CO}_{2}$-philic domains in GOPEGDA membrane; (b) Gas permeation performances of various GO-PEGDA membranes; (Both are adapted from Ref. [88], copyright 2017, with permission from WILEY-VCH Verlag $\mathrm{GmbH} \&$ Co. KGaA, Weinheim.) (c) Schematic illustration of $\mathrm{H}_{2-}$ permeance through TUGOF; (d) Permeances of gases through TU-GOF membrane; (Both are adapted from Ref. [94], copyright 2018, with permission from WILEY-VCH Verlag GmbH \& Co. KGaA, Weinheim.) (e) Schematic portrayal of gas diffusion pathways in GO-SILM membrane fabrication; (f) Comparison of gas separation performances of GO-SILM membrane with GO. (Adapted from Ref. [97], copyright 2018, with permission from American Chemical Society.) 
a crucial role in dispersing the GO stacks, thereby producing much-ordered composite membranes. The fabrication process generally involves the coating of GO-ionic liquid dispersions onto the porous supports under alkaline conditions. Karunakaran et al..$^{95}$ used two imidazolium based ionic liquids $-(\mathrm{emim})(\mathrm{Ac})$ and $(\mathrm{emim})\left(\mathrm{BF}_{4}\right)$ for making membranes on polyacrylonitrile supports via a simple dip-coating process followed by room temperature drying. The resultant membranes displayed excellent $\mathrm{CO}_{2}$ separation features $\left(\mathrm{CO}_{2}\right.$ flux $=37 \mathrm{GPU} ; \mathrm{CO}_{2} / \mathrm{N}_{2}$ selectivity $\left.=130\right)$ with marked stability. Chen's team also employed (emim) $\left(\mathrm{BF}_{4}\right)$ for fabricating membranes on PEBAX 1657 block copolymers under similar conditions. ${ }^{96}$ The respective $\mathrm{CO}_{2}$ permeance (1000 GPU) reached very high but the $\mathrm{CO}_{2} / \mathrm{N}_{2}$ selectivity became poor. Ying et al. ${ }^{97}$ recently utilized AAO substrates and $(\mathrm{bmim})\left(\mathrm{BF}_{4}\right)$ for engineering $\mathrm{GO}$ membrane (GO-SILM) via vacuum filtration (Fig. 7e). This stable membrane exhibited a moderate $\mathrm{CO}_{2}$ permeance (68.5 GPU) with high selectivities of 24,234 and 382 for $\mathrm{CO}_{2} / \mathrm{H}_{2}, \mathrm{CO}_{2} / \mathrm{CH}_{4}$ and $\mathrm{CO}_{2} / \mathrm{N}_{2}$ separations respectively (Fig. 7f).

It is known that GO prone to wrinkle during the dispersion in polymeric matrix which reduces the permeability features of the final composite membranes. Hybrids having mechanically stable dopants can resolve this issue to some extent. Guo's group ${ }^{98}$ implemented this thought in their publication where they mixed GO nanoribbons (GONRs) with MWCNTs which provided the required firmness to the polyimide membrane (MWCNT@GONRs). The nanosized hollow structure and smooth internal surface of CNTs promoted the rapid transportation of gas molecules while the high dispersibility of GONRs shell provided the required gas selectivity, even at low loadings.

Similarly, it is also proven that the addition of zerodimensional nanoparticles can improve the gas diffusion via raising the free volume of polymeric membranes. Wang et al. ${ }^{99}$ deposited $\mathrm{TiO}_{2}$ nanoparticles $(<10 \mathrm{~nm})$ on $\mathrm{GO}$ surface via adsorption layer nanoreactor synthesis. Later, through in-situ polymerization of polyimide, they created homogeneous $\mathrm{TiO}_{2}-$ GO composite membranes. The small $\mathrm{TiO}_{2}$ particles successfully inhibited the $\mathrm{GO}$ aggregation, thereby, distributed GO homogeneously in polymeric matrix. The polar surface of $\mathrm{TiO}_{2}$ particles enhanced $\mathrm{CO}_{2}$ diffusion and is proportional to $\mathrm{TiO}_{2}$ content. In a recent notable report, Zeng's team ${ }^{100}$ developed an indirect route to fabricate a GO-based composite (rGO@MgO/C) with significant $\mathrm{CO}_{2}$ uptakes of 31.5 wt \% (27 ${ }^{\circ}$ $\mathrm{C}, 1 \mathrm{bar}$ ) and $22.5 \mathrm{wt} \%$ (under the simulated flue gas). Here, the in-situ generated amorphous carbon served as a dual carbon support and protective system which prevented the tentative agglomeration of $\mathrm{MgO}$ nanocrystallites. Similarly, Jiang's team ${ }^{101}$ decorated the GO stacks with $\mathrm{Zn}^{2+}$ ions by using polydopamine coating and embedded them into PEBAX matrix. The zinc ions are known for building a reversible $\pi$ - complexation with $\mathrm{CO}_{2}$ which fasten the $\mathrm{CO}_{2}$ migration (137.9 Barrer) across the $\mathrm{GO}$ with a reasonable selectivity $\left(\mathrm{CO}_{2} / \mathrm{CH}_{4}=\right.$ 30.6) due to the more tortuous diffusion pathways.

Besides GO, its hybrids with porous fillers like zeolites, metal-organic frameworks (MOFs) are also dispersed in polymeric matrices for improving the membrane's robustness and separation ability. Karanikolos's group ${ }^{102}$ integrated the inorganic ZIF-8/GO hybrid nanofillers into the organic PSF matrix via solution blending. The resulted mixed-matrix membranes $(\mathrm{PSF}+\mathrm{ZIF}-8 / \mathrm{GO})$ showed a sharp rise in $\mathrm{CO}_{2}$ permeability ( $61 \%$ vs pristine PSF) and selectivity $(87 \%$ vs pristine PSF) against $\mathrm{CH}_{4}$. But, when compared to PSF+ZIF8 mixed-matrix membranes, a 7-fold increment in selectivity is noticed. This enhancement is assigned to the synergic effect from ZIF-8 and GO where ZIF-8 furnished more affinity towards $\mathrm{CO}_{2}$ and $\mathrm{GO}$ created suitable hindered tortuous diffusion tracts. Similarly, Tavassoli's group imported the widely known MOF- $\mathrm{CuBTC}$ into polyvinylidene difluoride matrix where the free sites of $\mathrm{Cu}$ played a vital role in showing the remarkable gas separation features. ${ }^{103}$ The $\mathrm{He}$ and $\mathrm{CO}_{2}$ permeabilities are 10.066, 3.316 Barrer respectively and more than $100 \%$ increase is noted in $\mathrm{He} / \mathrm{CH}_{4}, \mathrm{He} / \mathrm{N}_{2}$ and $\mathrm{CO}_{2} /$ $\mathrm{CH}_{4}$ gas selectivity.

\section{New Synthetic Approaches}

Since most of the bottom-up fabrication methods for graphenerelated membranes are sensitive, complicated and hazardous, alternative synthetic approaches are on rise in the contemporary years. Surface-assisted and solution-mediated oxidative cyclizations of finely-structured polyphenylenes were developed to achieve nanometer-wide strips of graphene, termed as graphene nanoribbons (GNRs). Cai et al. ${ }^{104}$ described the first on-surface preparation of GNRs where 10,10'-dibromo9, 9'-bianthryl is first deposited in ultrahigh vacuum on a metallic surfaces such as $\mathrm{Au} / \mathrm{Ag} / \mathrm{Cu}(111)$, upon annealing, they polymerized and planarized. But, the large-scale fabrication is often very limited in this approach which can be realized by solution-mediated protocols which mainly consisted of two steps. In the first step, Suzuki, Yamamoto or Diels-Alder polymerization of tailor-made monomers will be carried out to get polyphenylenes which on second step, directly converted to GNRs by intramolecular oxidative cyclodehydrogenation (Scholl reaction).

Recently, Ali Coskun's team ${ }^{105}$ engineered graphene nanoribbons frameworks (GNFs) through Diels-Alder polymerization followed by $\mathrm{FeCl}_{3}$-catalyzed cyclodehydrogenation. An arylacetylene and a dicyclopentanedienone analog were used to construct GNRs (length $\sim 2 \mathrm{~nm}$, width $1.1 \mathrm{~nm}$ ) within GNFs. Large $\pi$-surface area with high microporosity $(\sim 5.8 \AA)$ led to a significant enhancement in gas affinities with an exceptional $\mathrm{CO}_{2} / \mathrm{CH}_{4}$ selectivity of 62.7 at $298 \mathrm{~K}$. This team further functionalized the edges of GNRs to 
build GNFs (Fig. 10a) having substituents, namely, -OMe (GNF-1), $-\mathrm{CF}_{3}$ (GNF-2) and - F (GNF-3) at precise positions. ${ }^{106}$ As depicted in Fig. 10b, all GNFs evinced remarkable separation performance for $\mathrm{CO}_{2} / \mathrm{CH}_{4}$ under simulated conditions at $25^{\circ} \mathrm{C}$. It is worthy to noted here that GNFs having fluoro substituents (GNF-2, GNF-3) showed higher affinities for perfluorocarbons and chlorofluorocarbons.

\section{Challenges and Future Perspectives}

As outlined above, graphene-derived membranes have received a lot of attention for gas-separation applications and undergone notable progress in the recent past. In this review, we have briefly portrayed the current state of research regarding the preparation, structure of various graphene-derived membranes like mono and few-layered nanoporous graphene membranes, free-standing $\mathrm{GO}$ membranes, $\mathrm{GO} /$ polymer composite membranes with an emphasis on their gas-separation performance. Intriguing results regarding their superior separation and significant selectivity in multiple gas mixtures have been discussed, however, it is to be noted that these graphene-derived membranes are still at nascent stage and several obstacles still need to overcome for their implementation in practical separation processes.

From synthesis point of view, the scalability and reproducibility of graphene materials with same properties via facile routes are quite challenging. Much advancement in dispersion methods, pore engineering techniques, membrane fabrication and transfer strategies are required. Also, more studies should be conducted to comprehend the fundamental transport mechanisms involved. Endeavors such as suitable surface modifications that engender compatibility between polymers and G-derivatives, suppressing the plasticization of polymers and taking the advantage of the synergic effects of different-sized pores can improve the sustainability of these membranes towards the realistic environments like highhydrostatic pressures, harsh chemical conditions. These efforts may further boost their applications not only in oil and gas industry but also in other membrane-based industries like solar/ fuel cells and batteries.

\section{Acknowledgements}

This work was financially supported by the National Natural Science Foundation of China (Grant No. 21703119), the Natural Science Foundation of Shandong Province (Grant No. ZR2017MB036), the Grant for Taishan Scholar Advantage Characteristic Discipline, the Start-up Grant for QiLu Young Scholars, the Danish National Research Foundation, AUFF NOVA-project, and EU H2020 RISE 2016 (MNR4SCell 734174 project). N. P. thanks Shandong University for postdoctoral fellowship.

\section{References}

1. Á. A. Ramírez-Santos, C. Castel and E. Favre, Sep. Purif. Technol., 2018, 194, 425-442.

2. M. G. Buonomenna, RSC Advances, 2013, 3, 5694.

3. R. W. Baker and B. T. Low, Macromolecules, 2014, 47, 6999-7013.

4. Z. X. Low, P. M. Budd, N. B. McKeown and D. A. Patterson, Chem. Rev., 2018, 118, 5871-5911.

5. M. Galizia, W. S. Chi, Z. P. Smith, T. C. Merkel, R. W. Baker and B. D. Freeman, Macromolecules, 2017, 50, 7809-7843.

6. B. Van der Bruggen, M. Mänttäri and M. Nyström, Sep. Purif. Technol., 2008, 63, 251-263.

7. M. Ulbricht, Polymer, 2006, 47, 2217-2262.

8. J. S. Chiou, J. W. Barlow and D. R. Paul, J. Appl. Polym. Sci., 1985, 30, 2633-2642.

9. K. S. Novoselov, A. K. Geim, S. V. Morozov, D. Jiang, Y. Zhang, S. V. Dubonos, I. V. Grigorieva and A. A. Firsov, Science, 2004, 306, 666-669.

10. D. Zhou and B. H. Han, Adv. Funct. Mater., 2010, 20, 2717-2722.

11. W. Yuan, J. Chen and G. Shi, Mater. Today, 2014, 17, 77-85.

12. S. Han, D. Wu, S. Li, F. Zhang and X. Feng, Adv. Mater., 2014, 26, 849864.

13. G. Liu, W. Jin and N. Xu, Chem. Soc. Rev., 2015, 44, 5016-5030.

14. P. Sun, K. Wang and H. Zhu, Adv. Mater., 2016, 28, 2287-2310.

15. L. Wang, M. S. H. Boutilier, P. R. Kidambi, D. Jang, N. G. Hadjiconstantinou and R. Karnik, Nat. Nanotechnol., 2017, 12, 509-522.

16. D. E. Jiang, V. R. Cooper and S. Dai, Nano Lett., 2009, 9, 4019-4024.

17. J. Abraham, K. S. Vasu, C. D. Williams, K. Gopinadhan, Y. Su, C. T. Cherian, J. Dix, E. Prestat, S. J. Haigh, I. V. Grigorieva, P. Carbone, A. K. Geim and R. R. Nair, Nat. Nanotechnol., 2017, 12, 546-550.

18. L. Chen, G. Shi, J. Shen, B. Peng, B. Zhang, Y. Wang, F. Bian, J. Wang, D. Li, Z. Qian, G. Xu, G. Liu, J. Zeng, L. Zhang, Y. Yang, G. Zhou, M. Wu, W. Jin, J. Li and H. Fang, Nature, 2017, 550, 380-383.

19. Q. Yang, Y. Su, C. Chi, C. T. Cherian, K. Huang, V. G. Kravets, F. C. Wang, J. C. Zhang, A. Pratt, A. N. Grigorenko, F. Guinea, A. K. Geim and R. R. Nair, Nat. Mater., 2017, 16, 1198-1202.

20. A. Morelos-Gomez, R. Cruz-Silva, H. Muramatsu, J. Ortiz-Medina, T. Araki, T. Fukuyo, S. Tejima, K. Takeuchi, T. Hayashi, M. Terrones and M. Endo, Nat. Nanotechnol., 2017, 12, 1083-1088.

21. K. G. Zhou, K. S. Vasu, C. T. Cherian, M. Neek-Amal, J. C. Zhang, H. Ghorbanfekr-Kalashami, K. Huang, O. P. Marshall, V. G. Kravets, J. Abraham, Y. Su, A. N. Grigorenko, A. Pratt, A. K. Geim, F. M. Peeters, K. S. Novoselov and R. R. Nair, Nature, 2018, 559, 236-240.

22. B. Mi, Science, 2014, 343, 740-742.

23. R. K. Joshi, P. Carbone, F. C. Wang, V. G. Kravets, Y. Su, I. V. Grigorieva, H. A. Wu, A. K. Geim and R. R. Nair, Science, 2014, 343, 752-754.

24. Y. Yang, X. Yang, L. Liang, Y. Gao, H. Cheng, X. Li, M. Zou, R. Ma, Q. Yuan and X. Duan, Science, 2019, 364, 1057.

25. K. H. Thebo, X. Qian, Q. Zhang, L. Chen, H. M. Cheng and W. Ren, Nat. Commun., 2018, 9, 1486.

26. R. Xiong, H. S. Kim, L. Zhang, V. F. Korolovych, S. Zhang, Y. G. Yingling and V. V. Tsukruk, Angew. Chem., Int. Ed., 2018, 57, 8508-8513.

27. J. Wang, P. Chen, B. Shi, W. Guo, M. Jaroniec and S. Z. Qiao, Angere. Chem., Int. Ed. , 2018, 57, 6814-6818.

28. Q. Xie, M. A. Alibakhshi, S. Jiao, Z. Xu, M. Hempel, J. Kong, H. G. Park and C. Duan, Nat. Nanotechnol., 2018, 13, 238-245.

29. K. Erickson, R. Erni, Z. Lee, N. Alem, W. Gannett and A. Zettl, Adv. Mater, 2010, 22, 4467-4472.

30. A. Ambrosi, C. K. Chua, A. Bonanni and M. Pumera, Chem. Rev., 2014, 114, 7150-7188.

31. M. E. Itkis, F. Borondics, A. Yu and R. C. Haddon, Nano Lett., 2007, 7, 900904.

32. I. K. Moon, J. Lee, R. S. Ruoff and H. Lee, Nat. Commun., 2010, 1, 73.

33. M. Lozada-Hidalgo, S. Hu, O. Marshall, A. Mishchenko, A. N. Grigorenko, R. A. W. Dryfe, B. Radha, I. V. Grigorieva and A. K. Geim, Science, 2016, 
351, 68-70.

34. Z. Fan, Q. Zhao, T. Li, J. Yan, Y. Ren, J. Feng and T. Wei, Carbon, 2012, 50, 1699-1703.

35. P. Russo, A. Hu, G. Compagnini, W. W. Duley and N. Y. Zhou, Nanoscale, 2014, 6, 2381-2389.

36. S. Kim, M. Henry and A. G. Fedorov, Appl. Phys. Lett., 2015, 107, 233102.

37. S. P. Surwade, S. N. Smirnov, I. V. Vlassiouk, R. R. Unocic, G. M. Veith, S. Dai and S. M. Mahurin, Nat. Nanotechnol., 2015, 10, 459-464.

38. M. Bieri, M. Treier, J. Cai, K. Aït-Mansour, P. Ruffieux, O. Gröning, P. Gröning, M. Kastler, R. Rieger, X. Feng, K. Müllen and R. Fasel, Chem. Commun., 2009, 45, 6919-6921.

39. D. Zhou, Y. Cui, P. W. Xiao, M. Y. Jiang and B. H. Han, Nat. Commun., 2014, 5, 4716.

40. J. William S. Hummers, and Richard E. Offeman, J. Am. Chem. Soc., 1958, 80, 1339.

41. Y. S. a. E. T. Samulski, Nano Lett., 2008, 8, 1679-1682.

42. G. Wang, J. Yang, J. Park, X. Gou, B. Wang, H. Liu and J. Yao, J. Phys. Chem. C, 2008, 112, 8192-8195.

43. P. Steurer, R. Wissert, R. Thomann and R. Mulhaupt, Macromol. Rapid Commun., 2009, 30, 316-327.

44. M. J. McAllister, J. L. Li, D. H. Adamson, H. C. Schniepp, A. A. Abdala, J. Liu, M. Herrera-Alonso, D. L. Milius, R. Car, R. K. Prud'homme and I. A. Aksay, Chem. Mater., 2007, 19, 4396-4404.

45. H. Kim, A. A. Abdala and C. W. Macosko, Macromolecules, 2010, 43, 65156530.

46. D. R. Dreyer, S. Park, C. W. Bielawski and R. S. Ruoff, Chem. Soc. Rev., 2010, 39, 228-240.

47. D. A. Dikin, S. Stankovich, E. J. Zimney, R. D. Piner, G. H. Dommett, G. Evmenenko, S. T. Nguyen and R. S. Ruoff, Nature, 2007, 448, 457-460.

48. C. K. Chua and M. Pumera, Chem. Soc. Rev., 2014, 43, 291-312.

49. H. Huang, Y. Ying and X. Peng, J. Mater. Chem. A, 2014, 2, 13772-13782.

50. L. C. Lin and J. C. Grossman, Nat. Commun., 2015, 6, 8335.

51. C. Huang, H. Wu, K. Deng, W. Tang and E. Kan, Phys. Chem. Chem. Phys., 2014, 16, 25755-25759.

52. Y. Tao, Q. Xue, Z. Liu, M. Shan, C. Ling, T. Wu and X. Li, ACS Appl. Mater. Interfaces, 2014, 6, 8048-8058.

53. Z. Tian, S. M. Mahurin, S. Dai and D. E. Jiang, Nano Lett., 2017, 17, 18021807.

54. C. Sun and B. Bai, J. Phys. Chem. C, 2018, 122, 6178-6185.

55. J. S. Bunch, S. S. Verbridge, J. S. Alden, A. M. van der Zande, J. M. Parpia, H. G. Craighead and P. L. McEuen, Nano Lett., 2008, 8, 2458-2462.

56. M. S. H. Boutilier, D. Jang, J. C. Idrobo, P. R. Kidambi, N. G. Hadjiconstantinou and R. Karnik, ACS Nano, 2017, 11, 5726-5736.

57. K. V. Agrawal, J. D. Benck, Z. Yuan, R. P. Misra, A. Govind Rajan, Y. Eatmon, S. Kale, X. S. Chu, D. O. Li, C. Gong, J. Warner, Q. H. Wang, D. Blankschtein and M. S. Strano, J. Phys. Chem. C, 2017, 121, 14312-14321.

58. L. Lin, L. Sun, J. Zhang, J. Sun, A. L. Koh, H. Peng and Z. Liu, Adv. Mater., 2016, 28, 4671-4677.

59. Y. Hao, M. S. Bharathi, L. Wang, Y. Liu, H. Chen, S. Nie, X. Wang, H. Chou, C. Tan, B. Fallahazad, H. Ramanarayan, C. W. Magnuson, E. Tutuc, B. I. Yakobson, K. F. McCarty, Y. W. Zhang, P. Kim, J. Hone, L. Colombo and R. S. Ruoff, Science, 2013, 342, 720-723.

60. X. Li, W. Cai, J. An, S. Kim, J. Nah, D. Yang, R. Piner, A. Velamakanni, I. Jung, E. Tutuc, S. K. Banerjee, L. Colombo and R. S. Ruoff, Science, 2009, 324, 1312-1314.

61. S. Bae, H. Kim, Y. Lee, X. Xu, J. S. Park, Y. Zheng, J. Balakrishnan, T. Lei, H. R. Kim, Y. I. Song, Y. J. Kim, K. S. Kim, B. Ozyilmaz, J. H. Ahn, B. H. Hong and S. Iijima, Nat. Nanotechnol., 2010, 5, 574-578.

62. T. Kobayashi, M. Bando, N. Kimura, K. Shimizu, K. Kadono, N. Umezu, K. Miyahara, S. Hayazaki, S. Nagai, Y. Mizuguchi, Y. Murakami and D. Hobara, Appl. Phys. Lett., 2013, 102, 023112.

63. M. O. Paraense, T. H. R. da Cunha, A. S. Ferlauto and K. C. de Souza Figueiredo, J. Appl. Polym. Sci., 2017, 134, 45521.
64. S. Huang, M. Dakhchoune, W. Luo, E. Oveisi, G. He, M. Rezaei, J. Zhao, D. T. L. Alexander, A. Zuttel, M. S. Strano and K. V. Agrawal, Nat. Commun., 2018, 9, 2632.

65. G. H. J. Zhao, S. Huang, L. F. Villalobos, M. Dakhchoune, H. Bassas, K. V. Agrawal, Sci. Adv., 2019, 5, eaav1851.

66. Z. Yuan, J. D. Benck, Y. Eatmon, D. Blankschtein and M. S. Strano, Nano Lett., 2018, 18, 5057-5069.

67. L. Liu, S. Ryu, M. R. Tomasik, E. Stolyarova, N. Jung, M. S. Hybertsen, M. L. Steigerwald, L. E. Brus and G. W. Flynn, Nano Lett., 2008, 8, 1965-1970.

68. S. P. Koenig, L. Wang, J. Pellegrino and J. S. Bunch, Nat. Nanotechnol., 2012, 7, 728-732.

69. H. W. Kim, H. W. Yoon, S. M. Yoon, B. M. Yoo, B. K. Ahn, Y. H. Cho, H. J. Shin, H. Yang, U. Paik, S. Kwon, J. Y. Choi and H. B. Park, Science, 2013, 342, 91-95.

70. K. Celebi, J. Buchheim, R. M. Wyss, A. Droudian, P. Gasser, I. Shorubalko, J. I. Kye, C. Lee and H. G. Park, Science, 2014, 344, 289-292.

71. M. S. Boutilier, N. G. Hadjiconstantinou and R. Karnik, Nanotechnology, 2017, 28, 184003

72. H. Li, Z. Song, X. Zhang, Y. Huang, S. Li, Y. Mao, H. J. Ploehn, Y. Bao and M. Yu, Science, 2013, 342, 95-98.

73. R. R. Nair, H. A. Wu, P. N. Jayaram, I. V. Grigorieva and A. K. Geim, Science, 2012, 335, 442-444.

74. H. W. Kim, H. W. Yoon, B. M. Yoo, J. S. Park, K. L. Gleason, B. D. Freeman and H. B. Park, Chem. Commun., 2014, 50, 13563-13566.

75. C. Chi, X. Wang, Y. Peng, Y. Qian, Z. Hu, J. Dong and D. Zhao, Chem. Mater., 2016, 28, 2921-2927.

76. B. Qi, X. He, G. Zeng, Y. Pan, G. Li, G. Liu, Y. Zhang, W. Chen and Y. Sun, Nat. Commun., 2017, 8, 825.

77. J. Zhu, X. Meng, J. Zhao, Y. Jin, N. Yang, S. Zhang, J. Sunarso and S. Liu, J. Membr. Sci., 2017, 535, 143-150.

78. L. Olivieri, S. Ligi, M. G. De Angelis, G. Cucca and A. Pettinau, Ind. Eng. Chem. Res., 2015, 54, 11199-11211.

79. Y. Shin, E. Prestat, K. G. Zhou, P. Gorgojo, K. Althumayri, W. Harrison, P. M. Budd, S. J. Haigh and C. Casiraghi, Carbon, 2016, 102, 357-366.

80. K. Althumayri, W. J. Harrison, Y. Shin, J. M. Gardiner, C. Casiraghi, P. M. Budd, P. Bernardo, G. Clarizia and J. C. Jansen, Phil. Trans. R. Soc. A, 2016, 374, 20150031.

81. A. Gonciaruk, K. Althumayri, W. J. Harrison, P. M. Budd and F. R. Siperstein, Microporous Mesoporous Mater., 2015, 209, 126-134.

82. K. Zahri, K. C. Wong, P. S. Goh and A. F. Ismail, RSC Advances, 2016, 6, 89130-89139.

83. E. A. Feijani, A. Tavassoli, H. Mahdavi and H. Molavi, J. Appl. Polym. Sci, 2018, 135, 46271.

84. S. Quan, S. W. Li, Y. C. Xiao and L. Shao, Int. J. Greenhouse Gas Control, 2017, 56, 22-29.

85. J. Shen, G. Liu, K. Huang, W. Jin, K.-R. Lee and N. Xu, Angew. Chem., Int. Ed., 2015, 127, 588-592.

86. J. Shen, G. Liu, K. Huang, Z. Chu, W. Jin and N. Xu, ACS Nano, 2016, 10, 3398-3409.

87. D. Pierleoni, M. Minelli, S. Ligi, M. Christian, S. Funke, N. Reineking, V. Morandi, F. Doghieri and V. Palermo, ACS Appl. Mater. Interfaces, 2018, 10, $11242-11250$

88. S. Wang, Y. Xie, G. He, Q. Xin, J. Zhang, L. Yang, Y. Li, H. Wu, Y. Zhang, M. D. Guiver and Z. Jiang, Angere. Chem., Int. Ed., 2017, 56, 14246-14251.

89. J. Heo, M. Choi, J. Chang, D. Ji, S. W. Kang and J. Hong, Sci. Rep., 2017, $7,456$.

90. Y. Dai, X. Ruan, Z. Yan, K. Yang, M. Yu, H. Li, W. Zhao and G. He, Sep. Purif. Technol., 2016, 166, 171-180.

91. B. S. Ge, T. Wang, H. X. Sun, W. Gao and H. R. Zhao, Polym. Adv. Technol., 2018, 29, 1334-1343.

92. T. Wang, C. Cheng, L. G. Wu, J. N. Shen, B. Van der Bruggen, Q. Chen, D. Chen and C. Y. Dong, Environ. Sci. Technol., 2017, 51, 6202-6210.

93. L. G. Wu, C. H. Yang, T. Wang and X. Y. Zhang, Appl. Surf. Sci., 2018, 440, 
1063-1072.

94. J. Yang, D. Gong, G. Li, G. Zeng, Q. Wang, Y. Zhang, G. Liu, P. Wu, E. Vovk, Z. Peng, X. Zhou, Y. Yang, Z. Liu and Y. Sun, Adv. Mater., 2018, 30, e1705775.

95. M. Karunakaran, L. F. Villalobos, M. Kumar, R. Shevate, F. H. Akhtar and K. V. Peinemann, J. Mater. Chem. A, 2017, 5, 649-656.

96. W. Fam, J. Mansouri, H. Li, J. Hou and V. Chen, ACS Appl. Mater. Interfaces, 2018, 10, 7389-7400.

97. W. Ying, J. Cai, K. Zhou, D. Chen, Y. Ying, Y. Guo, X. Kong, Z. Xu and X. Peng, ACS Nano, 2018, 12, 5385-5393.

98. Q. Xue, X. Pan, X. Li, J. Zhang and Q. Guo, Nanotechnology, 2017, 28, 065702.

99. T. Wang, C. H. Yang, C. L. Man, L. G. Wu, W. L. Xue, J. N. Shen, B. Van der Bruggen and Z. Yi, Ind. Eng. Chem. Res., 2017, 56, 8981-8990.

100. P. Li and H. C. Zeng, Environ. Sci. Technol., 2017, 51, 12998-13007.

101. D. Peng, S. Wang, Z. Tian, X. Wu, Y. Wu, H. Wu, Q. Xin, J. Chen, X. Cao and Z. Jiang, J. Membr. Sci., 2017, 522, 351-362.

102. S. Anastasiou, N. Bhoria, J. Pokhrel, K. S. Kumar Reddy, C. Srinivasakannan, K. Wang and G. N. Karanikolos, Mater. Chem. Phys., 2018, 212, 513-522.

103. E. A. Feijani, H. Mahdavi and A. Tavassoli, New J. Chem., 2018, 42, 1201312023.

104. J. Cai, P. Ruffieux, R. Jaafar, M. Bieri, T. Braun, S. Blankenburg, M. Muoth, A. P. Seitsonen, M. Saleh, X. Feng, K. Mullen and R. Fasel, Nature, 2010, 466, 470-473.

105. Y. Byun and A. Coskun, Chem. Mater., 2015, 27, 2576-2583.

106. Y. Byun, M. Cho, D. Kim, Y. Jung and A. Coskun, Macromolecules, 2017, 50, 523-533.

Publisher's Note Engineered Science Publisher remains neutral with regard to jurisdictional claims in published maps and institutional affiliations. 